\title{
Case Report \\ Heart Failure and Hypothermia in an Infant: Pseudocyanide Syndrome?
}

\author{
J. Scott Baird \\ Department of Pediatrics, Division of Critical Care Medicine, Columbia University, New York, NY, USA \\ Correspondence should be addressed to J. Scott Baird; jsb106@cumc.columbia.edu
}

Received 12 November 2017; Revised 5 February 2018; Accepted 14 February 2018; Published 1 April 2018

Academic Editor: Kenneth S. Waxman

Copyright (c) 2018 J. Scott Baird. This is an open access article distributed under the Creative Commons Attribution License, which permits unrestricted use, distribution, and reproduction in any medium, provided the original work is properly cited.

\begin{abstract}
Purpose. Mixed or central venous oxygen saturation has not been described during concurrent heart failure and hypothermia in children, both of which may be associated with hyperlactatemia. This report of an infant with heart failure and hypothermia is significant for increased inferior vena cava (IVC) oxygen saturation and hyperlactatemia. Case Report. A 36-day-old female was fussy for a day and then developed respiratory distress. In the Pediatric ER, she was tachycardic ( 260 beats/minute) and hypothermic (32.4 degrees C) with prolonged capillary refill and faint distal pulses. Adenosine was given twice via an intraosseous line for supraventricular tachycardia, with conversion to sinus rhythm. Blood drawn from an IVC catheter was significant for uncorrected (for temperature) oxygen saturation of $94 \%$ and lactate $18 \mathrm{mmol} / \mathrm{L}$; corrected and uncorrected IVC oxygen saturation early during rewarming were $>90 \%$. During rewarming, declines in uncorrected IVC oxygen saturation and lactate correlated. Hypothermia and hyperlactatemia resolved after 10 and 12 hours. Conclusions. Concurrent heart failure and hypothermia in an infant were associated with increased IVC oxygen saturation and hyperlactatemia, similar to lab findings associated with a mitochondrial toxin such as cyanide. Improvement of heart failure and hypothermia were associated with resolution of these lab abnormalities, thus helping to rule out mitochondrial toxins. Additional reports may help better define a pseudocyanide syndrome in this setting.
\end{abstract}

\section{Introduction}

Mixed or central venous oxygen saturation $\left(\mathrm{SO}_{2}\right)$ is decreased with heart failure and increased with hypothermia; though normal limits for mixed or central venous $\mathrm{SO}_{2}$ require interpretation within a clinical context, levels below $70 \%$ and above $90 \%$ are concerns [1]. Hyperlactatemia is common to both heart failure and hypothermia. With concurrent heart failure and hypothermia in children, hyperlactatemia is increased in proportion to heart failure severity [2], but mixed or central venous $\mathrm{SO}_{2}$ data are lacking. This report of an infant with heart failure and hypothermia is notable for increased inferior vena cava (IVC) $\mathrm{SO}_{2}$ and hyperlactatemia, similar to the findings associated with a mitochondrial toxin, such as cyanide.

\section{Case Report}

The Columbia University Medical Center IRB (AAAR0802) exempted this retrospective case report from review.
A 36-day-old female was fussy for a day and then developed respiratory distress. She was born at term, and a New York State newborn screen was negative. In the Pediatric ER, she was tachycardic ( 260 beats/minute) and hypothermic (32.4 degrees $\mathrm{C}$ ) with prolonged capillary refill and faint distal pulses. She was placed on continuous positive airway pressure via nasal prongs. Adenosine was given twice via an intraosseous line for supraventricular tachycardia with conversion to sinus rhythm. She was then intubated for worsening respiratory distress and placed on an $\mathrm{FiO}_{2}$ of 1.0. An echocardiogram was notable for decreased biventricular systolic function and left to right shunting through a patent foramen ovale. A dobutamine infusion was started. Arterial cannulation was unsuccessful; transcutaneous pulse $\mathrm{SO}_{2}$ was consistently $100 \%$ during rewarming. Results from the first blood gas (all blood gas results were reported uncorrected for temperature) drawn from a catheter placed in the IVC (by Seldinger technique; sutured in place after advancing to its full length overlying the $\mathrm{L} 3$ vertebral body; Figure 1) were $\mathrm{pH}$ 7.01, $\mathrm{PCO}_{2} 33 \mathrm{~mm} \mathrm{Hg}, \mathrm{PO}_{2} 101 \mathrm{~mm} \mathrm{Hg}, \mathrm{SO}_{2} 94 \%$, 


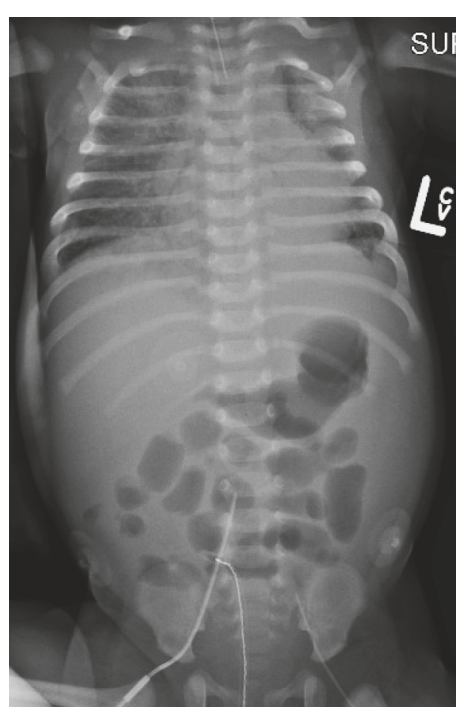

FIGURE 1: Radiograph of infant with heart failure and mild hypothermia showing central venous catheter overlying L3 vertebral body.

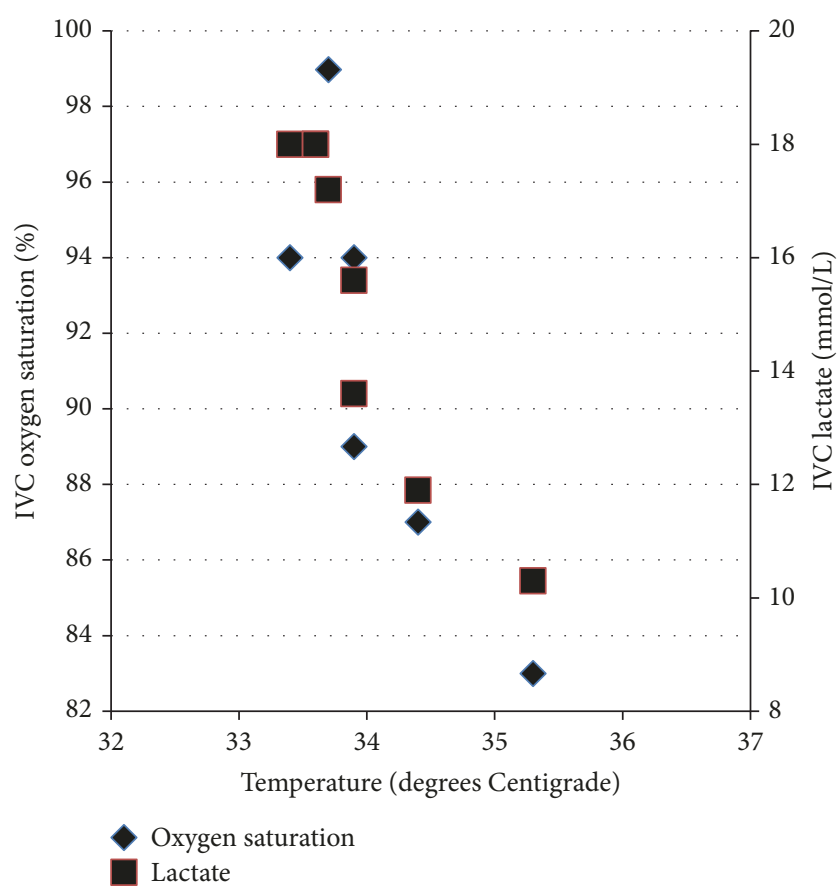

Figure 2: Inferior vena cava oxygen saturation (uncorrected for temperature) and lactate during rewarming of infant with heart failure and mild hypothermia.

and lactate $18 \mathrm{mmol} / \mathrm{L}$. Early during rewarming, the $\mathrm{IVC} \mathrm{SO}_{2}$ remained above $90 \%$ and was as high as $99 \%$ (Figure 2); declines in IVC $\mathrm{SO}_{2}$ and lactate during the first 3 hours of rewarming correlated (Spearman $r$ : 0.94; $p=0.002$ ). An arterial catheter was then placed, and the $\mathrm{FiO}_{2}$ weaned. B-type natriuretic peptide was increased $(4578.5 \mathrm{pg} / \mathrm{mL})$. Capillary refill and distal pulses improved, and dobutamine was discontinued at 8 hours; a repeat echocardiogram the next day showed improved (though still diminished) biventricular systolic function with continued left to right shunting through a patent foramen ovale. Hypothermia and hyperlactatemia resolved over 10 and 12 hours, and IVC $\mathrm{SO}_{2}$ was $80 \%$ on hospital day 2 . The patient was diagnosed with supraventricular tachycardia secondary to Wolff-ParkinsonWhite syndrome. Prior to discharge a week later, serum acylcarnitine profile, lactate, pyruvate, thyroid stimulating hormone, and thyroxine were all normal.

IVC $\mathrm{PO}_{2}$ values were corrected retrospectively for the patient's temperature [3] (Table 1).

\section{Discussion}

Concurrent acute heart failure and mild ( $>32$ degrees Centigrade [4]) hypothermia were associated with an increased $\mathrm{SO}_{2}$, profound metabolic acidosis, and severe hyperlactatemia in blood from the IVC of an infant. Heart failure alone is associated with a decreased mixed venous or central venous $\mathrm{SO}_{2}$-as well as a decreased IVC $\mathrm{SO}_{2}$-in neonates [5] as well as infants and children; mild hypothermia alone is associated with an increased-though still normal-mixed venous [6] or central venous [7] $\mathrm{SO}_{2}$ and is unlikely to be responsible for profound acidosis [4] or severe hyperlactatemia $[8,9]$. Resolution of heart failure and mild hypothermia in this infant was associated with resolution of the lab abnormalities: a decrease in cardiac output and tissue metabolic rate, as well as peripheral vasoconstriction and vascular shunting, all improved with resolution of heart failure and hypothermia. Similar lab abnormalities are associated with cyanide toxicity $[10,11]$, though the pathophysiology is different: as oxidative phosphorylation is disrupted, oxygen extraction and consumption decrease due to the metabolic block, and venous $\mathrm{SO}_{2}$ increases with hyperlactatemia. Though a metabolic disease or toxin might have been associated with the clinical presentation of this infant, there was ultimately no evidence to support such a diagnosis or its associated pathophysiology.

A clinical controversy regarding blood gas results may have escaped the notice of some pediatric intensivists: correcting blood gas results for the patient's temperature is no longer routine, as recommended [12]. As a result, blood gas specimens are routinely analyzed at 37 degrees Centigrade (normothermia) and so reported. Interestingly, correcting the blood gas results retrospectively in this infant did not alter the findings: early during rewarming (on the first 3 blood gas results), the corrected IVC $\mathrm{PO}_{2}$ was $>80 \mathrm{~mm} \mathrm{Hg}$, corresponding generally to $\mathrm{SO}_{2}$ values on the flat upper part of the oxyhemoglobin dissociation curve. As calculations of $\mathrm{SO}_{2}$ from $\mathrm{PO}_{2}$ may be associated with inaccuracies [13], specific $\mathrm{SO}_{2}$ values were not calculated; however, a leftward shift of the oxyhemoglobin dissociation curve (due both to hypothermia and the presence of fetal hemoglobin in a 5 week old infant) supports IVC $\mathrm{SO}_{2}$ values $>90 \%$ for $\mathrm{PO}_{2}$ values $>80 \mathrm{~mm} \mathrm{Hg}$. It is thus evident that both corrected and uncorrected IVC $\mathrm{SO}_{2}$ values early during rewarming were increased above normal.

The IVC $\mathrm{SO}_{2}$ was $>90 \%$ in $27 \%$ ( 15 of 55) of values from 20 critically ill neonates and infants undergoing cardiopulmonary bypass (mostly with hypothermia), though lactate was only mildly elevated (mean: $2.2+/-0.1 \mathrm{mmol} / \mathrm{L}$ ) [14]. 


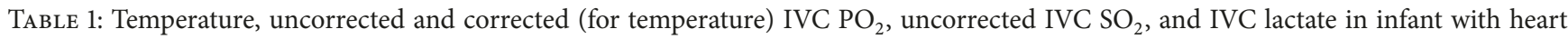
failure and mild hypothermia.

\begin{tabular}{|c|c|c|c|c|c|}
\hline $\begin{array}{l}\text { Time } \\
\text { (minutes) } \\
\end{array}$ & $\begin{array}{c}\text { Temperature (degrees } \\
\text { Centigrade) }\end{array}$ & $\begin{array}{c}\text { Uncorrected } \\
\mathrm{PO}_{2}(\mathrm{~mm} \mathrm{Hg}) \\
\end{array}$ & $\begin{array}{c}\text { Corrected } \mathrm{PO}_{2} \\
(\mathrm{~mm} \mathrm{Hg})\end{array}$ & $\begin{array}{c}\text { Uncorrected } \\
\mathrm{SO}_{2}(\%) \\
\end{array}$ & $\begin{array}{c}\text { Lactate } \\
(\mathrm{mmol} / \mathrm{L})\end{array}$ \\
\hline 0 & $33.4^{*}$ & 101 & 83 & 94 & 18 \\
\hline 63 & $33.6^{*}$ & 100 & 84 & 97 & 18 \\
\hline 74 & $33.7^{*}$ & 174 & 134 & 99 & 17.2 \\
\hline 87 & $33.9^{*}$ & 71 & 58 & 94 & 15.6 \\
\hline 106 & 33.9 & 59 & 48 & 89 & 13.6 \\
\hline 133 & 34.4 & 60 & 50 & 87 & 11.9 \\
\hline 177 & $35.3^{*}$ & 49 & 44 & 83 & 10.3 \\
\hline
\end{tabular}

${ }^{*}$ Interpolated temperatures.

As cardiopulmonary bypass replaces cardiac function, it is possible that heart failure with mild hypothermia in an infant would be associated with more severe hyperlactatemia and an increased IVC $\mathrm{SO}_{2}$, as noted in this infant. In any case, the trend in lab results from the IVC catheter was consistent during rewarming following cardioversion and suggests that these findings represent an actual association.

Limitations to this report include those related to retrospective case reports generally. Some laboratory dataincluding arterial blood gas results as well other metabolic testing-were not available due to limited vascular access during acute illness. The $\mathrm{FiO}_{2}$ was maintained at 1.0 during the first 3 hours of rewarming while the infant's clinical condition stabilized, and this could have contributed to an increased IVC SO $\mathrm{S}_{2}$; however, this effect was not dramatic, as the IVC $\mathrm{SO}_{2}$ fell to $83 \%$ before the $\mathrm{FiO}_{2}$ was weaned. In any case, pediatric intensivists may benefit from knowing that the $\mathrm{SO}_{2}$ from a femoral vascular catheter may be as high as $99 \%$ in certain clinical conditions, even when the catheter is not arterial. As the IVC catheter was advanced to its full length and sutured in place overlying the L3 vertebral body, proximal catheter migration was not possible, such that the left to right shunt across the patent foramen ovale did not contribute to an increased IVC SO 2 .

\section{Conclusion}

This report offers anecdotal evidence that $\mathrm{IVC} \mathrm{SO}_{2}$ may not always be low in infants with heart failure, while lactic acidosis may be profound in the presence of mild hypothermia: concurrent heart failure and mild hypothermia were likely responsible for the lab abnormalities in this infant, which to some extent mimic the lab abnormalities associated with a mitochondrial toxin such as cyanide. Further study of a pseudocyanide syndrome associated with concurrent heart failure and mild hypothermia in infants may be helpful.

\section{Disclosure}

This study was presented in abstract form at the 2017 American Thoracic Society's Annual meeting [15].

\section{Conflicts of Interest}

The author has no conflicts of interest relevant to this article to disclose.

\section{References}

[1] K. R. Walley, "Use of central venous oxygen saturation to guide therapy," American Journal of Respiratory and Critical Care Medicine, vol. 184, no. 5, pp. 514-520, 2011.

[2] S. B. Shinde, K. K. Golam, P. Kumar, and N. D. Patil, "Blood lactate levels during cardiopulmonary bypass for valvular heart surgery," Annals of Cardiac Anaesthesia, vol. 8, no. 1, pp. 39-44, 2005.

[3] G. R. Kelman and J. F. Nunn, "Nomograms for correction of blood Po2, Pco2, pH, and base excess for time and temperature," Journal of Applied Physiology, vol. 21, no. 5, pp. 1484-1490, 1966.

[4] M. L. Mallet, "Pathophysiology of accidental hypothermia," QJM: Monthly Journal of the Association of Physicians, vol. 95, no. 12, pp. 775-785, 2002.

[5] F. B. Plötz, R. A. Van Lingen, and A. P. Bos, "Venous oxygen measurements in the inferior vena cava in neonates with respiratory failure," Critical Care, vol. 2, no. 2, pp. 57-60, 1998.

[6] A. Bacher, U. M. Illievich, R. Fitzgerald, G. Ihra, and C. K. Spiss, "Changes in oxygenation variables during progressive hypothermia in anesthetized patients," Journal of Neurosurgical Anesthesiology, vol. 9, no. 3, pp. 205-210, 1997.

[7] Z. Hu, L. Xu, Z. Zhu, R. Seal, and P. M. McQuillan, "Effects of hypothermic cardiopulmonary bypass on internal jugular bulb venous oxygen saturation, cerebral oxygen saturation, and bispectral index in pediatric patients undergoing cardiac surgery: A prospective study," Medicine (United States), vol. 95, no. 2, Article ID e2483, 2016.

[8] Q.-J. Zhao, X.-G. Zhang, and L.-X. Wang, "Mild hypothermia therapy reduces blood glucose and lactate and improves neurologic outcomes in patients with severe traumatic brain injury," Journal of Critical Care, vol. 26, no. 3, pp. 311-315, 2011.

[9] J. Pirnes and T. Ala-Kokko, "Accidental hypothermia: factors related to long-term hospitalization. A retrospective study from northern Finland," Internal and Emergency Medicine, pp. 1-9, 2016.

[10] M. M. Yeh, C. E. Becker, and A. I. Arieff, "Is measurement of venous oxygen saturation useful in the diagnosis of cyanide 
poisoning?" American Journal of Medicine, vol. 93, no. 5, pp. 582-583, 1992.

[11] J. C. Pham, D. T. Huang, F. T. McGeorge, and E. P. Rivers, "Clarification of cyanide's effect on oxygen transport characteristics in a canine model," Emergency Medicine Journal, vol. 24, no. 3, pp. 152-156, 2007.

[12] E. R. Ashwood, G. Kost, and M. Kenny, "Temperature correction of blood-gas and $\mathrm{pH}$ measurements," Clinical Chemistry, vol. 29, no. 11, pp. 1877-1885, 1983.

[13] P. A. Johnson, D. J. Bihari, R. F. Raper, M. A. Haughton, M. M. Fisher, and R. G. Herkes, "A comparison between direct and calculated oxygen saturation in intensive care," Anaesthesia and Intensive Care, vol. 21, no. 1, pp. 72-75, 1993.

[14] M. Redlin, A. Koster, M. Huebler et al., "Regional differences in tissue oxygenation during cardiopulmonary bypass for correction of congenital heart disease in neonates and small infants: Relevance of near-infrared spectroscopy," The Journal of Thoracic and Cardiovascular Surgery, vol. 136, no. 4, pp. 962967, 2008.

[15] J. S. Baird, "Hypothermia and Acute Heart Failure in an Infant: Pseudo-Cyanide Syndrome?" B67 Interesting and Unusual Pediatric Case Reports, vol. 195, pp. A4099-A4099, 2017. 


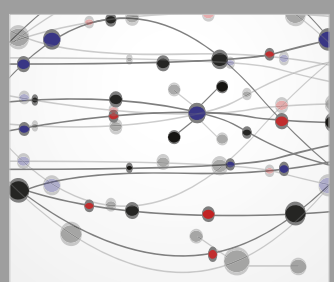

The Scientific World Journal
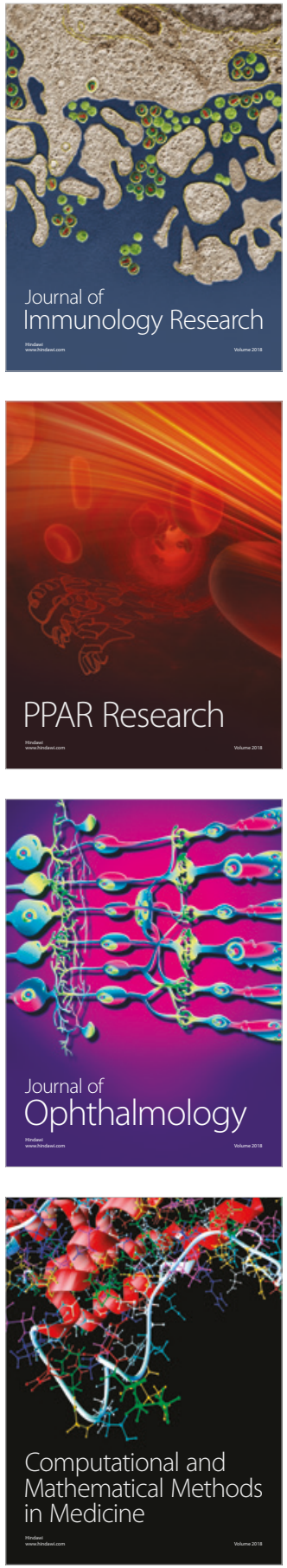

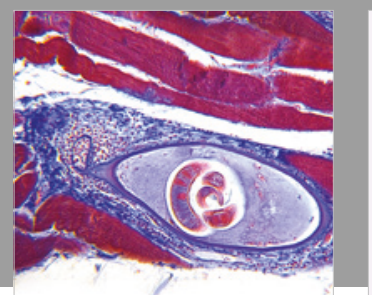

Gastroenterology Research and Practice

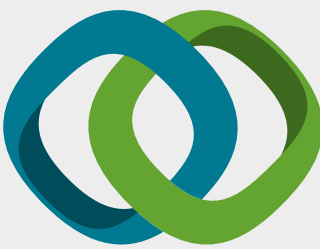

\section{Hindawi}

Submit your manuscripts at

www.hindawi.com
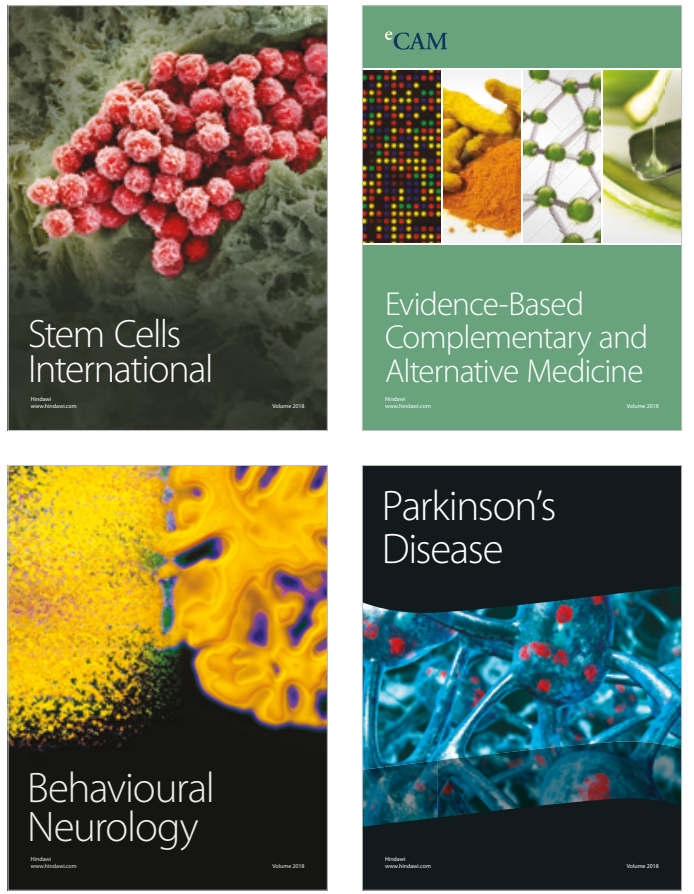

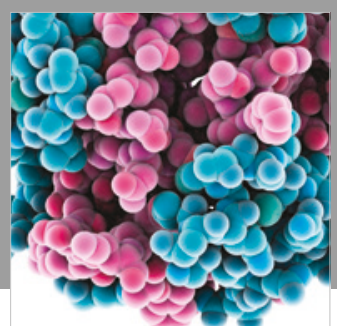

ournal of

Diabetes Research

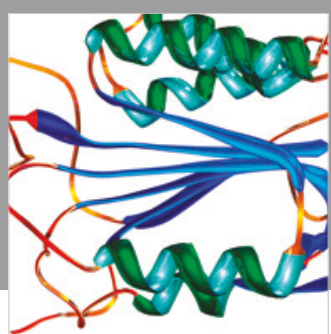

Disease Markers
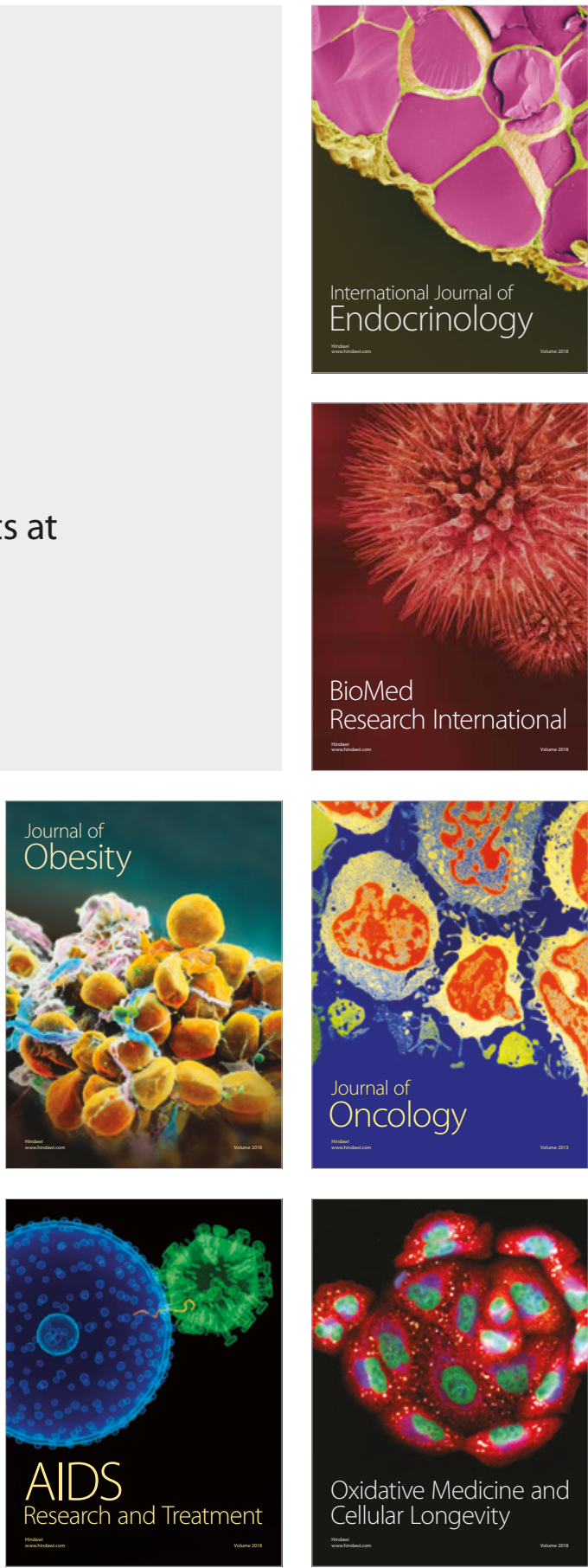